\title{
Improving mechanical behaviour of collapsible soils by grouting active clay nanoparticles
}

\author{
Ali Seiphoori ${ }^{1}$ and Mostafa Zamanian ${ }^{2}$ \\ ${ }^{1}$ Department of Earth, Atmospheric, and Planetary Sciences (EAPS), Massachusetts \\ Institute of Technology (MIT), Cambridge, MA, USA. Email: aliseiph@mit.edu \\ ${ }^{2}$ Faculty of Civil, Water, and Environmental Engineering, Shahid Beheshti University, \\ Tehran, Iran. Email:m_zamanian@sbu.ac.ir
}

\begin{abstract}
The primary geotechnical concern of collapsible soils such as loess is their hydromechanical instability. During (re)wetting, metastable aggregates disintegrate leading soil to collapse under the applied load or self-weight. In situ chemical stabilisation, such as grouting, is a favoured option to improve the mechanical behaviour of soils; however, the low permeability of loess limits the application of permeation grouting in such deposits. Here a new approach is presented based on the injection of dilute suspensions of montmorillonite clay nanoparticles to improve mechanical behaviour of a low permeable loess. In addition to clay, the grouting behaviour of an ordinary cement material was also evaluated as a typically favoured soil stabiliser. Reconstituted specimens were also prepared by mixing dry clay or cement particles with soil at similar contents and curing time to allow a comparison with the grouting method. Results revealed that clay suspensions feature a high-mobility in the soil medium as well as a remarkable performance in reducing the collapse potential due to: (1) clay effective particle size $(\sim 0.25 \mu \mathrm{m})$ that facilitates its mobility in soil, and (2) formation of strong, capillary-driven solid bridges that reinforce the interparticle bonds during post grouting evaporation. These results encourage the application of clay nanoparticles over cements for a sustainable, economical and eco-friendly grouting approach to improve the mechanical behaviour of low permeable collapsible soils.
\end{abstract}


Keywords: Collapsible soils; Soil improvement; Clay nanoparticles; Grouting; Solid bridges

\section{INTRODUCTION}

More than $10 \%$ of the land worldwide is composed of collapsible soils, such as loess deposits, mainly in arid and semiarid regions (Gaaver 2012; Assadi-Langroudi et al. 2018). The primary geotechnical concern of the unsaturated, metastable-structured loess deposits is their significant volume change when subject to increasing mechanical stress or decreasing matric suction (e.g., during (re)wetting), or combination of both (Popescu 1986; Jiang et al. 2014; Haeri et al. 2014; Boixadera et al. 2015). Loess is an aeolian sediment formed by aggregation of predominantly silt-sized particles (mode $20-60 \mu \mathrm{m})$ with often a small fraction of clays, typically in the range of 15-20\% wt (Mitchell et al. 2005; Indraratna et al. 2015). The aggregates have a relatively loose, open structure often featured by weak interparticle cementation bonds (Smalley and Vita-Finzi 1968; Coudé-Gaussen 1987; Mitchell et al. 2005; Assadi-Langroudi et al. 2018). Upon hydration, bonds are reduced and the inter-aggregate contacts fail during shear, leading them to collapse under the applied load or even the self-weight (Dudley 1970; Barden et al. 1973; Pereira and Fredlund 2000). Such wetting-induced collapse mechanism can cause a reduction of the total soil volume by up to $15 \%$ (Waltham 2002). Mechanical loading followed by wetting can be problematic when building civil engineering structures on loess deposits, where the water content varies due to intermittent precipitation events, irrigation, or change in the ground water level (Clevenger 1956; Handy 1973).

Various techniques have been used to improve the mechanical behaviour of collapsible soils including compaction and replacement (Mechanical methods), and stabilisation (Chemical method). Chemical stabilisers include, but are not limited to, cements (Horpibulsuk et al. 2010; Mohamed and El Gamal 2012), polymers (Arulrajah et al. 2016; Latifi et al. 2016; Ayeldeen et al. 2017), fly ash (Arulrajah et al. 2016), 
inorganic salts (Abbeche et al. 2010) and bituminous materials (Hoy et al. 2016). The treatment often involves mixing soil with stabilisers (Ghadir and Ranjbar 2018), or grouting the soil with solutions containing reactive particles such as cement, resin or lime (Ibragimov 2005; Gallagher et al. 2007). Due to the low permeability of loess deposits, the in site treatment methods using cements are limited to mainly mixing, soil piles, and compaction grouting.

While ordinary Portland cement and lime are the most favoured materials in soil stabilisation, chemical degradation under for instance internal sulfate attack (Schmidt et al. 2009; Neville 2004) impose a threat for the long-term stability and functionality of such soil binders. Furthermore, the production of cements raises several environmental concerns, including high carbon dioxide emission, dust generation, and source material depletion (Bosoaga et al. 2009; Fatehi et al. 2018). In recent years, application of nanomaterials to enhance the hydromechanical behaviour of fine-grained soils with less environmental drawbacks has received increasing attention (Luo et al. 2012; Taha and Taha 2012; Iranpour et al. 2016; Bahmani et al. 2014; Latifi et al. 2015; Latifi et al. 2016). Among various nano-sized additives such as copper, alumina, and silica particles, mixing clay nanoparticles with soils is reported to decrease the soil collapse potential, giving rise to a sustainable and environmentally friendly soil stabiliser (Iranpour et al. 2016; Latifi et al. 2016; Latifi et al. 2017). Clay minerals are one of the most stable and abundant materials on the earth surface with less processing efforts required compared to other synthesised stabilisers such as cements.

Less attention has been paid to permeation grouting to enhance the hydromechanical behaviour of low permeable loess deposits mainly due to their low hydraulic conductivity. Permeation grouting involves injection of a solution or slurry containing stabilising material in soil porous structure, where the grout will eventually turn into soil binders. The binders increase the mechanical strength of the soil structure by typically forming chemically-induced interparticle bonds such as calcium silicate hydrate (C-S-H). A uni- 
form distribution of the grout in soil medium increases grouting efficiency, and is thus economically favourable. Grout typically has large water content and will be subject to evaporation immediately after injection. Aside from the chemical processes involved in most grouts such as cement slurry, the variation of capillary suction upon evaporation may play a significant role in the grout-soil interactions and the final formation of soil binders. Seiphoori et al. (2020) experimentally showed that when suspensions containing polydisperse particles are subject to evaporation, capillary suction condenses small particles $(<5 \mu \mathrm{m}$ size $)$ in the capillary bridges formed between larger grains. After evaporation of the solvent (e.g., water), small particles turn into solid bridges that significantly increase the interparticle strength, giving rise to an effective cohesion (Seiphoori et al. 2020). Smectite-based clay minerals such as montmorillonite are characterised by nano-sized particles and large specific surface area. Evaporationinduced bonds formed by montmorillonite nanoparticles might improve the collapsible soil behaviour; however, to the authors' knowledge, application of clay nanoparticles as a grout in stabilising collapsible formations is not yet investigated.

Here we use montmorillonite nanoparticles for grouting a collapsible loess deposit. Large undisturbed loess samples were injected using solutions with different clay contents, and after a certain curing time, the 1-D collapse potential of the grouted materials were determined in the laboratory. Ordinary cement slurry was also used to represent the most favoured grout in practice and to compare with clay. Furthermore, reconstituted specimens were prepared by mixing clay or cement particles with the loess material at similar additive contents and curing times to allow a comparison with the grouting results. 


\section{MATERIALS AND METHOD}

\section{Materials}

\section{Natural collapsible soil}

The collapsible soil material was collected from Semnan Province located in the subtropical areas of Iran. After removing about the top soil $(\sim 50 \mathrm{~cm})$ from the original ground surface, thin-walled cylindrical samplers were used to acquire undisturbed material with dimensions of $35 \mathrm{~cm} \times 35 \mathrm{~cm}$. The material was then sealed using paraffin and transported to the laboratory. The basic physical and engineering properties of the tested soil material are listed in Table 1. The Atterberg limits and specific gravity of the soil were measured for three samples using the ASTM D4318 and ASTM D854 methods, respectively. The unit weight of the soil was determined at the site using the sand-cone method (ASTM D1556-07). The index properties indicate that the fines content primarily consist of silt. Furthermore, the soil particle size distribution was determined using dry sieving and hydrometer tests (for $\mathrm{d}<75 \mu \mathrm{m}$ ) as shown in Fig. 1-A. The soil is thus classified as low plasticity silt. Fig. 1-B presents scanning electron photomicrographs of the soil aggregates, where the porous microfabric is observed to consist of fine sand grains bonded by silt/clay-sized particles (see the inset image). The scanning electron microscope (Hitachi SU3500; Japan) was operated under high vacuum conditions at $15 \mathrm{keV}$ of accelerating voltage in a backscattered electron mode. The hydraulic conductivity of the soil was evaluated using the falling head method (ASTM D5084, initial water height of $100 \mathrm{~cm}$ ) with an average value of $7.7 \times 10^{-6} \mathrm{~m} / \mathrm{s}$ which implies a low permeable silt-based soil. The collapse index of the undisturbed and reconstituted specimens from the untreated soil studied here was evaluated to be $9.1 \%$ and $11.3 \%$, respectively, with moderately sever to sever degree of collapsibility based on ASTM D5333 (see Figure 3-C). 


\section{Soil stabilisers}

In this study, Na-montmorillonite clay (NC) and ordinary Portland cement (OPC) were used as soil stabilisers. Montmorillonite is a naturally occurring and reactive clay mineral which belongs to the smectite mineral group. Montmorillonite k10 (SigmaAldrich, USA) was used in this research, which is a highly porous substance with a larger surface area and nanopores. It is chemically modified by the cation-exchange method which results in reducing its swelling potential (Maiti et al. 2016; Alekseeva et al. 2019). When dry montmorillonite particles are mixed with water to establish the grouting solution, particles disperse upon further hydration. As time progresses, the dispersed montmorillonite particles may aggregate and form larger clusters. The particle size distribution of aqueous suspension of montmorillonite particles in distilled water is presented in Figure 2 (Alekseeva et al. 2019), with an effective particle size of $246 \mathrm{~nm}$. The montmorillonite clay features a large specific surface area, $\mathrm{S}_{B E T}=195$ $\mathrm{m}^{2} / \mathrm{g}$ (Alekseeva et al. 2019), and ion exchange capacity of about $48 \mathrm{meq} / 100 \mathrm{~g}$ (SigmaAldrich, USA).

The cement used in this study was type II Portland (OPC) according to ASTM C150, obtained from Gharb Cement Manufacturing in Iran. The specific surface area of the OPC was evaluated to be $0.32 \mathrm{~m}^{2} / \mathrm{g}$, significantly lower than that of the NC material. The particle size distribution of the cement is also presented in Figure 2-B with a dominant particle size of $\sim 13.3 \mu \mathrm{m}, 1-2$ orders of magnitude larger than that of the NC effective particle size.

\section{Sample preparation}

\section{Soil grouting setup}

A schematic view of the grouting system designed in this research is presented in Figure 3-A. The system comprised a fluid tank positioned within an adjustable frame to inject slurry under a constant initial pressure head $\left(h_{0}\right)$ by changing the elevation 
of the fluid tank. The scaling factor of the injection setup was about $1 / 15$ of a typical full-scale injection system (Nichols and Goodings 2000; Iai et al. 2005). The grout solid content was considered based on the weight of the dry stabiliser particles per total weight of the cylindrical soil sample $(\sim 30 \mathrm{~kg})$. Solid contents of $0.5,1$, and 2.5 $w t . \%$ for $\mathrm{OPC}$, and $0.05,0.1$, and $0.25 w t . \%$ for $\mathrm{NC}$ were selected. It is noted that the OPC contents are one order of magnitude larger than $\mathrm{NC}$ contents for grouting similar soil volume to achieve comparable impacts on the soil collapse index. The grout was prepared by mixing dry particles with $1 \mathrm{~L}$ of deionized water. As a result, the water content of OPC and NC grouts varies in the range of (57-87\%) and (93-98\%), respectively. Mixing was conducted using a lab mixer for a short period of $2 \mathrm{~min}$. Prior to injection the surface of the samples was flattened and an injection hole was drilled by rotating an open-ended tube with an outer diameter of $7 \mathrm{~mm}$ down into the undisturbed sample along its height. The slurry was transmitted from the fluid tank into the soil through a connection tube, where it was injected uniformly using a perforated rod (holes of $0.6 \mathrm{~mm}$ diameter and spacing of $2.0 \mathrm{~cm}$ along the rod). The injection pressure which is a function of soil overburden pressure is a key parameter of grouting performance. Different grouting heads were applied to determine an optimum initial grouting pressure head. Surface rupture was observed at high injection pressures $(>14$ $\mathrm{kPa})$ and low grout penetration at low hydraulic pressure $(<4 \mathrm{kPa})$. The optimum injection pressure was thus obtained to be about $7 \mathrm{kPa}$, approximately 1.5 times greater than the soil maximum in-situ overburden pressure. As the injection proceeds, the pressure head drops and after a given period of time the tank supply is exhausted (i.e., injection under a falling head). We note that, under the above-described conditions, the $\mathrm{NC}$ grout solution takes up to about 2 min to be injected through the soil matrix, while cement grout taking up to $20 \mathrm{~min}$ at higher concentration likely due to the difference in their effective aggregate size and thus their mobility in soil porous structure (Figure 2-B) and the soil pore size distribution. After grouting, the samples were cured for 
7, 14 and 28 days under open air condition with $\mathrm{T}=30 \pm 6^{\circ} \mathrm{C}$ and $\mathrm{RH}=21 \pm 11 \%$ (with average annual variations of $\mathrm{T}=22 \pm 14^{\circ} \mathrm{C}$ and $\mathrm{RH}=43 \pm 33 \%$ recorded for the loess site location). Undisturbed specimens were then taken from the centre and corners of the grouted sample (see Figure 3-A) and trimmed to evaluate their collapse potential in an oedometer cell (Figure 3-B).

\section{Soil mixing}

A number of specimens were reconstituted to compare with the grouted materials. Oven-dried soil was homogeneously mixed with dry cement or clay particles and then reconstituted in an odometer mould at dry unit weight and water contents consistent with that of the in situ material (i.e., $\gamma_{d}=14 \mathrm{kN} / \mathrm{m}^{3}$ and $w=5 \%$ ). The additive contents of $0.5,1$, and $2.5 \mathrm{wt} . \%$ for OPC, and $0.05,0.1$, and $0.25 \mathrm{wt} . \%$ for $\mathrm{NC}$ were selected. A wet under-compaction method (Ladd 1978) was used to prepare specimens with uniform density along the specimen height. Similar to the grouted specimens, the collapse potential of the reconstituted specimens was determined after 7, 14, and 28 days.

\section{Collapse potential}

The 1-D soil collapse potential was determined through inundating the unsaturated soil specimens under a constant vertical stress in an oedometer device according to ASTM D5333. First, the specimens were incrementally $\left(\frac{\sigma_{v}[i+1]}{\sigma_{v}[i]} \sim 2, \sigma_{v}[0]=5 \mathrm{kPa}\right)$ loaded up to $\sigma_{v}[j]=200 \mathrm{kPa}$ under their initial water content with $1 \mathrm{~h}$ time intervals between each successive loading step. The specimens were inundated with distilled water after $1 \mathrm{~h}$ under $\sigma_{v}[j]=200 \mathrm{kPa}$ and the load was kept constant for $24 \mathrm{~h}$, and the specimen deformation was recorded continuously. The 1-D collapse potential at the onset of the sudden deformation upon inundation is defined by the collapse index, $I_{c}=\frac{\Delta h[j]}{h[j]}=\frac{\Delta e[j]}{1+e[j]}$, where $\Delta h[j]$ and $\Delta e[j]$ are the specimen settlement and variation of void ratio due to inundation at load increment $j$, and $h[j]$ and $e[j]$ are 
the specimen height and void ratio prior to collapse, respectively. The initial void ratios of the grouted specimens were calculated using the weight volume relationship by measuring the specimen's weight and water content. The collapse behaviour of the undisturbed and reconstituted specimens from the untreated loess studied here is presented in Figure 3-C. The undisturbed sample display larger compressibility and collapse behaviour which is likely associate with sensitivity of the natural interparticle bonds to the applied hydromechanical stress path. This indicates that the compaction during reconstituting the material slightly improved the mechanical behaviour of the loess.

\section{RESULTS}

\section{Stabilisation with active clay nanoparticles (NC)}

\section{Grouting}

The results of the compressibility behaviour of specimens acquired from the centre and side of the grouted column (see Figure 3-A) at $0.25 w t . \% \mathrm{NC}$ and different times after injection is presented in Figure 4-A and B, respectively. The collapse behaviour of the untreated soil is also shown in these plots. The collapse index of the centre and side specimens with different percentages of $\mathrm{NC}$ at 7, 14, and 28 days after treatment is also presented in Figure 4-C and D. The collapse index of the untreated soil decreased from $11.3 \%$ to less than $0.7,0.4$, and 0.3 for centre specimens grouted with $0.05 \%, 0.1 \%$ and $0.25 w t . \% \mathrm{NC}$, respectively, after 28 days. The optimum performance appears to be achieved at $0.1 w t . \% \mathrm{NC}$ content for both centre and side specimens. This indicates the high-mobility of the NC grout which was able to be uniformly distributed within the soil matrix increasing the interparticle strength. Furthermore, the gain of strength is likely completed in the early stages after grouting. The collapse index of the side specimens slightly increased when increasing NC content to $0.25 w t . \%$, indicating that the efficiency decreased at higher grout concentration. Formation of the clay clusters 
within the soil matrix can be observed in the SEM photomicrographs taken at various NC contents after 28 days curing (Figure 5). The NC agglomerates are observed to likely bind the soil grains/aggregates by forming interparticle bridges as well as filling the inter-aggregate pore spaces.

Mixing

The compressibility and collapse behaviour of the specimens prepared by mixing NC particles with soil is presented in Figure 6-A and B. Unlike the grouting, mixing appears to be much less effective in reducing soil collapse, especially at higher clay contents. Although mixing soil with NC particles is expected to result in a more homogeneous distribution of clay particles within the soil matrix, it appears that the sole presence of clay particles in the soil matrix does not result in the formation of interparticle bonds (see Figure 6-C and D) as it spontaneously does during grouting. Instead, coating particle surfaces likely contributes in reducing the soil strength by decreasing the internal friction (Taha and Taha 2012). These experiments suggest that in order to achieve a maximum performance in improving the mechanical behaviour of collapsible soils using clay nanoparticles, the clay must be grouted than mixed.

\section{Stabilisation with cement (OPC)}

\section{Grouting}

The compressibility behaviours of specimens acquired from the centre and side locations of the grouted material with $2.5 w t . \%$ OPC after different curing times are presented in Figure 7-A and B, respectively. The collapse index of the centre and side specimens with different percentages of OPC after 7, 14, and 28 days is also presented in Figure 7-C and D. While OPC has remarkably decreased the collapse index of the soil around the grouting hole, its performance on side specimens is not acceptable, especially at higher cement contents. The poor performance of cement at $2.5 w t . \%$ content is likely associated with a reduced hydraulic conductivity of the soil due to 
flocculation of cement particles and clogging the pores. The soil strength appears to be achieved during the first two weeks with an optimum performance for specimens grouted with $1 \mathrm{wt.} \%$ OPC content, where the collapse index decreased to $0.2 \%$ and $1.6 \%$ for the centre and side specimens, respectively. SEM photomicrograps of the materials from the centre and side specimens grouted with different OPC contents are presented in Figure 8. While the soil inter-grain/aggregate pores in the centre specimens are observed to be nearly filled with OPC material, the side specimens likely remained more porous. The lower porosity of the centre specimens is also discernible in consolidation graphs (Figure 7-A), where the initial void ratio has decreased from 0.9 to 0.75 . The change of initial void ratio of the side material is negligible (Figure 7-B) which implies that the OPC slurry was not able to penetrate the soil and fill the pores to decrease the porosity. This behaviour is consistent with the observation of the microfabric shown in Figure 8. The specimens grouted with 1 wt.\% OPC exhibits an optimum performance.

Mixing

The compressibility and collapse behaviour of the specimens prepared by mixing OPC material with soil is presented in Figure 9-A and B. Unlike the NC grout, an increase in OPC content improves mechanical behaviour of the studied soil by reducing the collapse index; however, the performance of mixing is significantly lower than that achieved by grouting, especially at lower cement contents. It is noted that the higher water content in grouting (57-86\%) compared to mixing ( $(5 \%)$ results in further hydration of the cement, where calcium silicate hydrate (C-S-H) bonds form and increase the soil strength. SEM photomicrograps of the OPC-treated specimens at different cement contents 28 days after mixing process are shown in Figure 9-C and D, where the inter-particle bonds formed by OPC material can be observed. 


\section{DISCUSSION}

The variation of the collapse index of the loess deposit 14 days after it was treated by mixing or grouting with the NC or OPC particles is presented in Figure 10. The collapse level of the untreated soil is also marked in the plot. Mixing NC at low content $(0.05 w t . \%)$ is more effective than the best performance achieved by OPC (at content of $2.5 w t . \%$ ), showing the efficiency of mixing NC particles with soil to improve mechanical behaviour with significantly less used material (i.e., 50 times less mass). The best performance of using NC particles as soil stabiliser was achieved through grouting small quantity $(0.1 w t . \%)$, which resulted in reducing the collapse index up to $96 \%$ (Figure 10). Although OPC grouting effectively reduces the collapse index of the material around the injection hole, its performance is largely impacted by the distance from the injection centre indicating its limited mobility. More importantly, the $\mathrm{NC}$ content is $1 / 10$ of the OPC used to achieve comparable results. It is worth noting from the OPC grout trends that there might be an optimum OPC percentage $(<0.5$ $w t . \%$ ), where the collapse index of the side and centre specimens of the studied loess reaches about $1 \%$; nevertheless, the application of $\mathrm{NC}$ is economically favourable and ecologically compatible.

Now the question is why grouting NC particles is remarkably effective (and efficient) in improving the the mechanical behaviour. The answer lies in two distinct features involved in the grouts of montmorillonite clay nanoparticles (NC) and the subsequent evaporation of the grout as time proceeds: (1) montmorillonite particles are remarkably smaller $(\sim 0.25 \mu \mathrm{m}$ size) than cement particles $(\sim 13 \mu \mathrm{m}$ size) (see Figure2-B), which facilitates their transport in soil porous skeleton; (2) subsequent evaporation of the grouted solution results in the formation of strong solid bridges which significantly increase the soil strength. Grout mobility in soil depends on a number of physical and chemical factors including the grout particle size and the pore size distribution of the soil medium as well as the interfacial interaction of the grout particles and soil grains 
(Semmler et al. 2000; Auset and Keller 2004; Bradford et al. 2002). Larger particles or aggregates are more likely to be trapped in narrow soil pore throats and thus prevent a uniform distribution of the grout in the soil matrix during injection. Modified KozenyCarman equation, $K=0.0898 \frac{D^{2}}{\mu} \gamma_{w} \phi^{3.4}$ (Lala 2018), results in an effective pore size, $D \sim 3 \mu \mathrm{m}$, where $K$ is the hydraulic conductivity of the tested soil (See Table 1), $\phi$ is the porosity (0.48), $\mu$ is the water viscosity, and $\gamma_{w}$ is the unit weight of water. It is noted that the soil permeability to $\mathrm{NC}$ grout is expected to be larger than the permeability obtained from falling head method which can potentially modify the pore structure; nevertheless, this equation provides an estimate of the effective pore size of the loess deposit studied here. This explains why the NC grout is more effective than OPC for the side specimens that are far from the injection hole. An increase in the clay content however encourages the formation of clay gel or weakly agglomerated particles that may clog the soil pore throats, and thus decrease the effective permeability of the soil matrix as seen for side specimen of $\mathrm{NC}$ grout at $0.25 \mathrm{wt} . \%$.

Immediately after injecting the grout, the solution will be subject to evaporation. The NC grout featuring a large initial water content (93-98\%) will follow a drying path similar to that described in Figure 11 (water retention data modified from (Seiphoori et al. 2014)). As evaporation proceeds, capillary bridges form between adjacent soil grains/aggregates, while the diminishing volume of the bridge leads NC particles to form a clay gel. Further evaporation under the relatively low humidity of the site (Average $\mathrm{RH} \sim 21 \%$ ) will turn the NC gel into solid structures that bind the particles and reinforce the interparticle bonds, giving rise to an effective cohesion (Figure 11). These bonds referred to as "solid bridges" can increase the interparticle strength by orders of magnitude (Seiphoori et al. 2020) depending on the grout effective particle size and its solid fraction in the capillary bridges. Seiphoori et al. (2020) show that this interparticle cohesive force originates from the sum of the van der Waals bonds within the solid bridges. 
Furthermore, unlike the OPC-grouted material, in NC-injected specimens, the mechanical improvement has been achieved in the early stages once the grout water is further evaporated. The much less quantity of NC particles does not drastically change the permeability of the soil, while the high content OPC grouting reduces the soil porosity and thus permeability. The disturbance to soil fabric and chemistry would be significantly minimised when NC particles are grouted as soil stabilisers.

\section{CONCLUSIONS}

Permeation grouting relies on the injection of grouts into soil porous skeleton to improve its mechanical properties through formation or reinforcement of soil interparticle bonds. The grout high-mobility in soil is a key parameter to optimise the cost and to predict the grouting end performance. The conventional permeation grouting is limited to soils which contain small fraction of fine particles $(<15 \%)$. On the other hand, the geochemical stability of the grout is important for the long-term performance of the grouted geomaterials. Here we presented a grouting approach based on injecting a low permeable collapsible soil with solutions containing montmorillonite clay nanoparticles. The clay particle size facilitates its mobility in soil, while its large specific surface area results in strong capillary-driven interparticle bonds (i.e., solid bridges). The solid bridges driven by evaporation form relatively fast, especially in the semi-arid/arid regions with geological formations susceptible to collapse upon rewetting. We showed that the formation of solid bridges is facilitated through grouting, and mixing same amount of dry clay material with soil does not lead to same results; coating soil grain surfaces with clay particles indeed reduces the soil strength by decreasing the internal friction. The montmorillonite clay is likely an ideal material to form solid bridges through providing a large number of microscopic contacts where the interfacial bonds form, giving rise to an effective cohesion. In order for increasing the mobility of conventional grouts, ultrafine cements are typically an option; however, the specific 
surface area of the cement does not increase significantly by reducing the particle size. For instance, an ultrafine cement with $90 w t . \%$ below $7.32 \mu \mathrm{m}$, the specific surface area is $0.725 \mathrm{~m}^{2} / \mathrm{g}$ (Sarkar and Wheeler 2001), orders of magnitude smaller than that of montmorillonite clay. Typical cement materials are susceptible to chemical degradation which impacts the long-term functionality of the grout, while clays typically exhibit high stability to chemical variation of the pore water. In addition, the production of cement raises several environmental concerns, such as the emission of carbon dioxide and depletion of the source material, encouraging the application of soil stabilisers with less processing efforts such as clays. Our results thus suggest the application of clay nanoparticles solutions for a fast, economical and more environmentally-friendly grouting approach compared to cements, which likely results in formation of chemically more stable interparticle bonds, and hence an improved performance of the grouted soils. The proposed approach may help to improve the mechanical behaviour of geomaterials susceptible to creep, liquefaction, or erosion which involve the disintegration of metastable soil aggregates.

\section{ACKNOWLEDGEMENT}

Authors would like to thank Ms. F. Qahremani for running permeability experiments, and Mr. A. Mansori for collecting undisturbed loess samples.

\section{NOTATION}

$d$ soil particle diameter

$D_{x}$ particle size for the finer material at which $\mathrm{x}$ percent of the material is finer

NC Na-montmorillonite/Nano-sized clay

OPC Ordinary Portland cement

$S_{B E T} \quad$ BET specific surface area

$h_{0} \quad$ initial grouting head

wt. weight ratio 
RH relative humidity

$V$ volume

$\sigma_{v} \quad$ vertical stress

$I_{c} \quad$ collapse index

$h$ specimen height

$e$ void ratio

$\Delta h$ height increment

$\Delta e$ void ratio increment

$K$ hydraulic conductivity

$D \quad$ effective pore size of soil

$\phi \quad$ soil porosity

$\mu \quad$ viscosity of water

$\gamma_{w} \quad$ unit weight of water

$\gamma_{d}$ dry unit weight of soil

$w_{0}$ initial water content

$w_{l}$ liquid limit water content

$w_{p} \quad$ plastic limit water content

PI Plastic Index

$G_{s} \quad$ solid particles specific gravity

\section{REFERENCES}

Abbeche, K., Bahloul, O., Ayadat, T., and Bahloul, A. (2010). “Treatment of collapsible soils by salts using the double consolidation method." Experimental and Applied Modeling of Unsaturated Soils, 69-78.

Alekseeva, O., Noskov, A., Grishina, E., Ramenskaya, L., Kudryakova, N., Ivanov, V., 
and Agafonov, A. (2019). "Structural and thermal properties of montmorillonite/ionic liquid composites." Materials, 12(16), 2578.

Arulrajah, A., Mohammadinia, A., Phummiphan, I., Horpibulsuk, S., and Samingthong, W. (2016). "Stabilization of recycled demolition aggregates by geopolymers comprising calcium carbide residue, fly ash and slag precursors." Construction and Building Materials, 114, 864-873.

Assadi-Langroudi, A., Ng'ambi, S., and Smalley, I. (2018). "Loess as a collapsible soil: Some basic particle packing aspects." Quaternary International, 469, 20-29.

Auset, M. and Keller, A. A. (2004). "Pore-scale processes that control dispersion of colloids in saturated porous media." Water Resources Research, 40(3).

Ayeldeen, M., Negm, A., El-Sawwaf, M., and Kitazume, M. (2017). "Enhancing mechanical behaviors of collapsible soil using two biopolymers." Journal of Rock Mechanics and Geotechnical Engineering, 9(2), 329-339.

Bahmani, S. H., Huat, B. B., Asadi, A., and Farzadnia, N. (2014). "Stabilization of residual soil using sio2 nanoparticles and cement." Construction and Building Materials, 64, 350-359.

Barden, L., McGown, A., and Collins, K. (1973). "The collapse mechanism in partly saturated soil." Engineering Geology, 7(1), 49-60.

Boixadera, J., Poch, R. M., Lowick, S. E., and Balasch, J. C. (2015). "Loess and soils in the eastern ebro basin." Quaternary international, 376, 114-133.

Bosoaga, A., Masek, O., and Oakey, J. E. (2009). “Co2 capture technologies for cement industry." Energy procedia, 1(1), 133-140.

Bradford, S. A., Yates, S. R., Bettahar, M., and Simunek, J. (2002). "Physical factors affecting the transport and fate of colloids in saturated porous media." Water resources research, 38(12), 63-1.

Clevenger, W. A. (1956). "Experiences with loess as foundation materials." Journal of the Soil Mechanics and Foundations Division, 82(3), 1-26. 
Coudé-Gaussen, G. (1987). "The perisaharan loess: sedimentological characterization and paleoclimatical significance." GeoJournal, 15(2), 177-183.

Dudley, J. H. (1970). "Review of collapsing soils.” Journal of the Soil Mechanics and Foundations Division, 96(3), 925-947.

Fatehi, H., Abtahi, S. M., Hashemolhosseini, H., and Hejazi, S. M. (2018). "A novel study on using protein based biopolymers in soil strengthening." Construction and Building Materials, 167, 813-821.

Gaaver, K. E. (2012). “Geotechnical properties of egyptian collapsible soils.” Alexandria Engineering Journal, 51(3), 205-210.

Gallagher, P. M., Pamuk, A., and Abdoun, T. (2007). "Stabilization of liquefiable soils using colloidal silica grout." Journal of Materials in Civil Engineering, 19(1), 33-40.

Ghadir, P. and Ranjbar, N. (2018). “Clayey soil stabilization using geopolymer and portland cement." Construction and Building Materials, 188, 361-371.

Haeri, S. M., Garakani, A. A., Khosravi, A., and Meehan, C. L. (2014). “Assessing the hydro-mechanical behavior of collapsible soils using a modified triaxial test device." Geotechnical Testing Journal, 37(2), 190-204.

Handy, R. L. (1973). “Collapsible loess in iowa 1.” Soil Science Society of America Journal, 37(2), 281-284.

Horpibulsuk, S., Rachan, R., Chinkulkijniwat, A., Raksachon, Y., and Suddeepong, A. (2010). "Analysis of strength development in cement-stabilized silty clay from microstructural considerations." Construction and building materials, 24(10), 20112021.

Hoy, M., Horpibulsuk, S., and Arulrajah, A. (2016). "Strength development of recycled asphalt pavement-fly ash geopolymer as a road construction material." Construction and Building Materials, 117, 209-219.

Iai, S., Tobita, T., and Nakahara, T. (2005). "Generalised scaling relations for dynamic centrifuge tests." Geotechnique, 55(5), 355-362. 
Ibragimov, M. (2005). "Soil stabilization with cement grouts." Soil mechanics and foundation engineering, 42(2), 67-72.

Indraratna, B., Chu, J., and Rujikiatkamjorn, C. (2015). Ground improvement case histories: compaction, grouting and geosynthetics. Butterworth-Heinemann.

Iranpour, B. et al. (2016). "The influence of nanomaterials on collapsible soil treatment." Engineering geology, 205, 40-53.

Jiang, M., Li, T., Hu, H., and Thornton, C. (2014). "Dem analyses of one-dimensional compression and collapse behaviour of unsaturated structural loess." Computers and Geotechnics, 60, 47-60.

Ladd, R. (1978). "Preparing test specimens using undercompaction." Geotechnical Testing Journal, 1(1), 16-23.

Lala, A. M. S. (2018). "Modifications to the kozeny-carman model to enhance petrophysical relationships.” Exploration Geophysics, 49(4), 553-558.

Latifi, N., Eisazadeh, A., Marto, A., and Meehan, C. L. (2017). “Tropical residual soil stabilization: A powder form material for increasing soil strength." Construction and Building Materials, 147, 827-836.

Latifi, N., Horpibulsuk, S., Meehan, C. L., Abd Majid, M. Z., Tahir, M. M., and Mohamad, E. T. (2016). "Improvement of problematic soils with biopolymer-an environmentally friendly soil stabilizer." Journal of Materials in Civil Engineering, 29(2), 04016204.

Latifi, N., Rashid, A. S. A., Siddiqua, S., and Horpibulsuk, S. (2015). "Micro-structural analysis of strength development in low-and high swelling clays stabilized with magnesium chloride solution-a green soil stabilizer." Applied Clay Science, 118, 195-206.

Luo, H.-L., Hsiao, D.-H., Lin, D.-F., and Lin, C.-K. (2012). “Cohesive soil stabilized using sewage sludge ash/cement and nano aluminum oxide.” International Journal of Transportation Science and Technology, 1(1), 83-99. 
Maiti, S., Pramanik, A., Chattopadhyay, S., De, G., and Mahanty, S. (2016). "Electrochemical energy storage in montmorillonite k10 clay based composite as supercapacitor using ionic liquid electrolyte." Journal of colloid and interface science, 464, 73-82.

Mitchell, J. K., Soga, K., et al. (2005). Fundamentals of soil behavior, Vol. 3. John Wiley \& Sons Hoboken, NJ.

Mohamed, A.-M. and El Gamal, M. (2012). “Treatment of collapsible soils using sulfur cement.” International Journal of Geotechnical Engineering, 6(1), 65-77.

Neville, A. (2004). “The confused world of sulfate attack on concrete." Cement and Concrete research, 34(8), 1275-1296.

Nichols, S. C. and Goodings, D. J. (2000). "Physical model testing of compaction grouting in cohesionless soil." Journal of Geotechnical and Geoenvironmental Engineering, 126(9), 848-852.

Pereira, J. H. and Fredlund, D. G. (2000). "Volume change behavior of collapsible compacted gneiss soil." Journal of geotechnical and geoenvironmental engineering, 126(10), 907-916.

Popescu, M. E. (1986). “A comparison between the behaviour of swelling and of collapsing soils.” Engineering Geology, 23(2), 145-163.

Sarkar, S. L. and Wheeler, J. (2001). "Important properties of an ultrafine cement—part i." Cement and Concrete Research, 31(1), 119-123.

Schmidt, T., Lothenbach, B., Romer, M., Neuenschwander, J., and Scrivener, K. (2009). "Physical and microstructural aspects of sulfate attack on ordinary and limestone blended portland cements." Cement and Concrete Research, 39(12), 1111-1121.

Seiphoori, A., Ferrari, A., and Laloui, L. (2014). "Water retention behaviour and microstructural evolution of mx-80 bentonite during wetting and drying cycles." Géotechnique, 64(9), 721-734.

Seiphoori, A., Ma, X.-g., Arratia, P. E., and Jerolmack, D. J. (2020). "Formation of 
stable aggregates by fluid-assembled solid bridges." Proceedings of the National Academy of Sciences, 117(7), 3375-3381.

Semmler, M., Rička, J., and Borkovec, M. (2000). "Diffusional deposition of colloidal particles: electrostatic interaction and size polydispersity effects." Colloids and Surfaces A: Physicochemical and Engineering Aspects, 165(1-3), 79-93.

Smalley, I. and Vita-Finzi, C. (1968). "The formation of fine particles in sandy deserts and the nature of" desert'loess.” Journal of Sedimentary Research, 38(3), 766-774.

Taha, M. R. and Taha, O. M. E. (2012). "Influence of nano-material on the expansive and shrinkage soil behavior.” Journal of Nanoparticle Research, 14(10), 1190.

Waltham, T. (2002). Foundations of engineering geology. CRC Press. 
This manuscript is submitted to Géotechnique

\section{List of Tables}

$1 \quad$ Physical and geomechanical properties of untreated collapsible soil . . 23 
This manuscript is submitted to Géotechnique

Table 1. Physical and geomechanical properties of untreated collapsible soil

\begin{tabular}{cccccccc}
\hline \hline$e_{0}$ & $\gamma_{d}\left(\frac{k N}{m^{3}}\right)$ & $w_{0}$ & $w_{l}$ & $w_{p}$ & PI & $G_{s}$ & $K(m / s)$ \\
\hline $0.95 \pm 0.03$ & $13.9 \pm 0.16$ & $4.67 \pm 0.47$ & $22.33 \pm 2.05$ & $19.67 \pm 1.24$ & $3.66 \pm 0.94$ & $2.69 \pm 0.01$ & $(7.7 \pm 0.2) \times 10^{-6}$
\end{tabular}




\section{List of Figures}

1 Particle size distribution and pore structure of the studied loess deposit: (A) Apparent particle size distribution obtained using dry sieving and hydrometry. (B) SEM photomicrograph showing the particle arrangement, where silt and clay size particles are observed to bridge the interparticle space of the larger granular grains, forming an open struc-

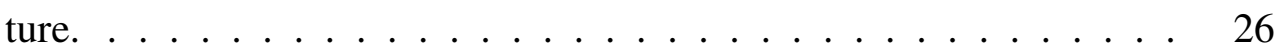

2 Particle size distribution of the montmorillonite k10 particles (NC) and ordinary Portland cement (OPC) used as soil stabilizers in this study. .

3 (A) Experimental setup developed for grouting the loess deposit studied here. (B) 1-D measurement of the collapse potential in oedometer cell. (C) Compressibility and collapse behavior of undisturbed and reconstituted specimens of the untreated loess obtained in the oedometer

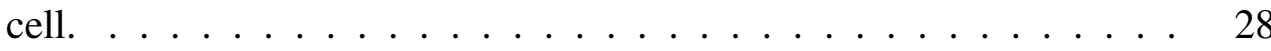

4 Mechanical stabilization of the studied loess through grouting montmorillonite clay nanoparticles (NC): (A), (B) compressibility and collapse behavior of the untreated and grouted materials for specimens acquired from the center and side of the grouted column. (C), (D) variation of collapse index at different NC contents and curing times after grouting for the center and side specimens, respectively. . . . . . . . .

5 SEM photomicrographs showing the microfabric of the grouted soil material using montmorillonite clay (NC) at various contents. The clay agglomerates are observed to likely bind the soil aggregates by forming interparticle bonds and fill the inter-aggregate pore space, particularly at larger contents. The arrows show the inter-grain/aggregate bonds formed by the clay assemblies. . . . . . . . . . . . 
6 Mechanical stabilization of the studied loess by mixing the soil with montmorillonite clay nanoparticles: (A) and (B) Compressibility and collapse behavior as a function of NC content. (C), (D) NC particle assemblies do not necessarily form interparticle bonds at the soil grain

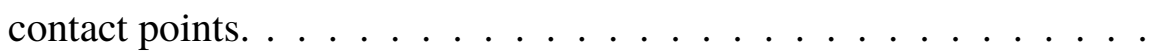

7 Mechanical stabilization of the studied loess through grouting ordinary Portlant cement (OPC): (A), (B) compressibility and collapse behavior of the untreated and grouted materials for specimens acquired from the center and side of the grouted column. (C), (D) variation of collapse index at different OPC contents and curing times after grouting for center and side specimens, respectively. . . . . . . . . . . . . 32

8 SEM photomicrographs showing the microfabric of the grouted soil material using Portland cement (OPC) at various contents. The arrows show the inter-grain/aggregate bonds formed by the cement bonds. .

9 Mechanical stabilization of the studied loess by mixing the soil with Portland cement (OPC): (A) and (B) compressibility and collapse behavior as a function of OPC content. (C), (D) SEM images showing the cement particles forming the inter-grain/aggregate bonds within the soil matrix. . . . . . . . . . . . . . . .

10 Mechanical stabilization of the loess material studied here through grouting the NC and OPC solutions or mixing the stabilizer particles with soil for 14 days curing time. In grouting data, the dashed and solid lines represent the side and center specimens, respectively. . . . . . 35

11 Formation of interparticle bonds during evaporation of the montmorillonite clay (NC) grout after injection. Capillary suction condense clay particles in the capillary bridges, where the clay gel turns into solid bridges after evaporation $\ldots \ldots \ldots \ldots$ 

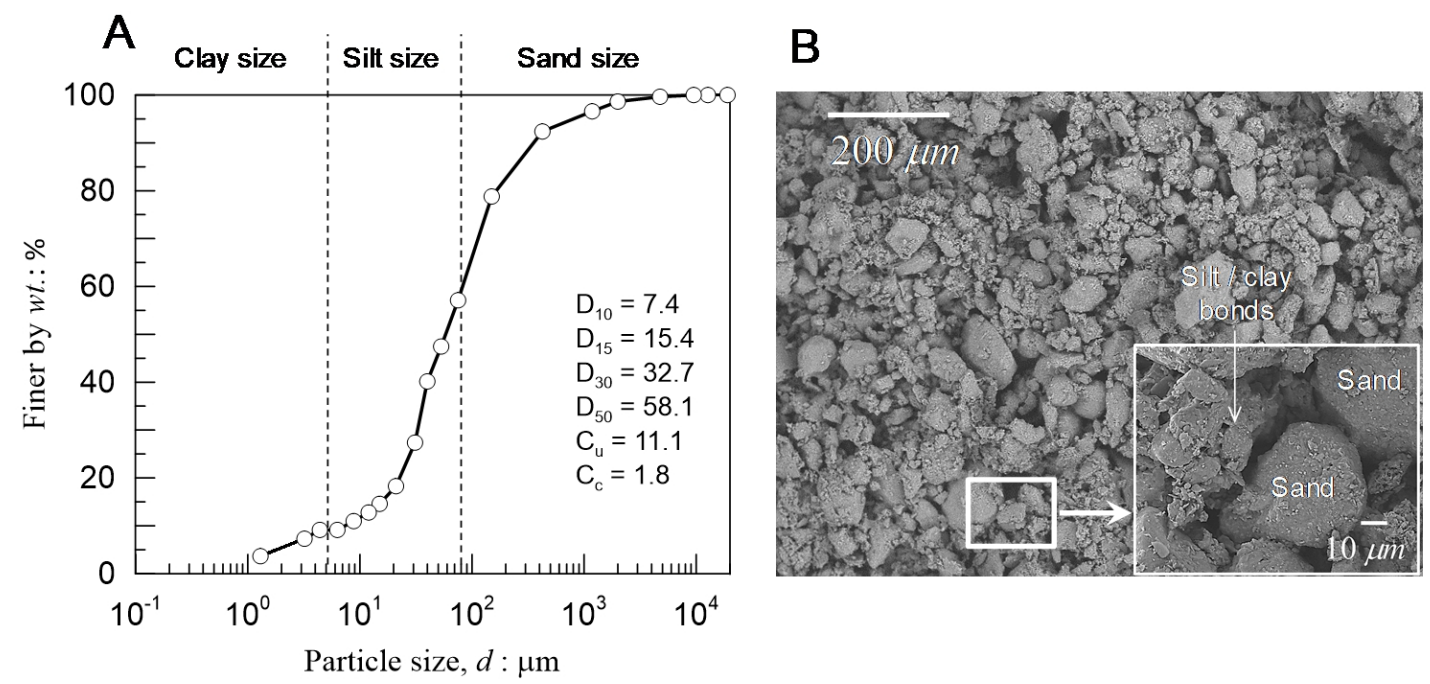

Fig. 1. Particle size distribution and pore structure of the studied loess deposit: (A) Apparent particle size distribution obtained using dry sieving and hydrometry. (B) SEM photomicrograph showing the particle arrangement, where silt and clay size particles are observed to bridge the interparticle space of the larger granular grains, forming an open structure. 


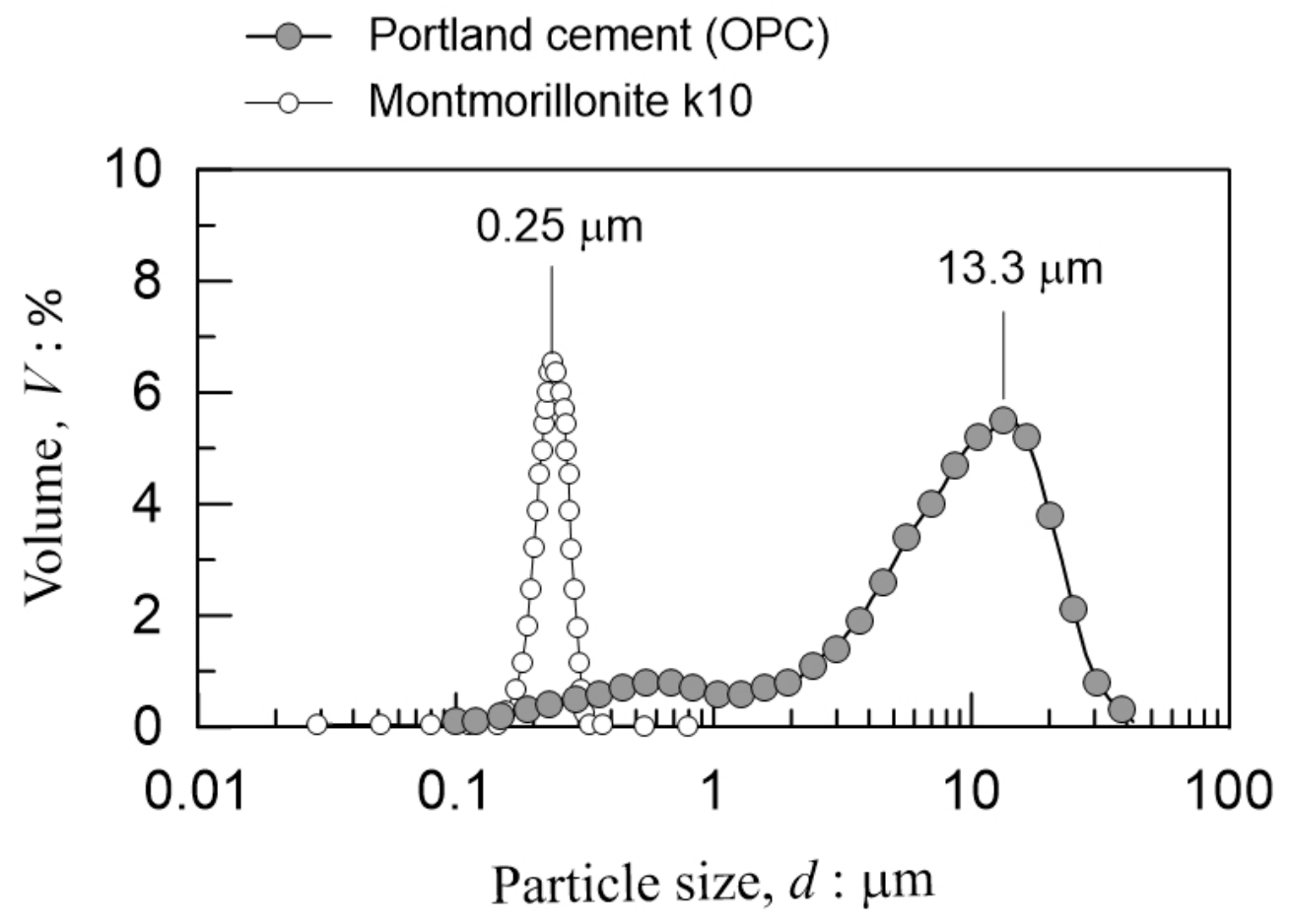

Fig. 2. Particle size distribution of the montmorillonite k10 particles (NC) and ordinary Portland cement (OPC) used as soil stabilizers in this study. 


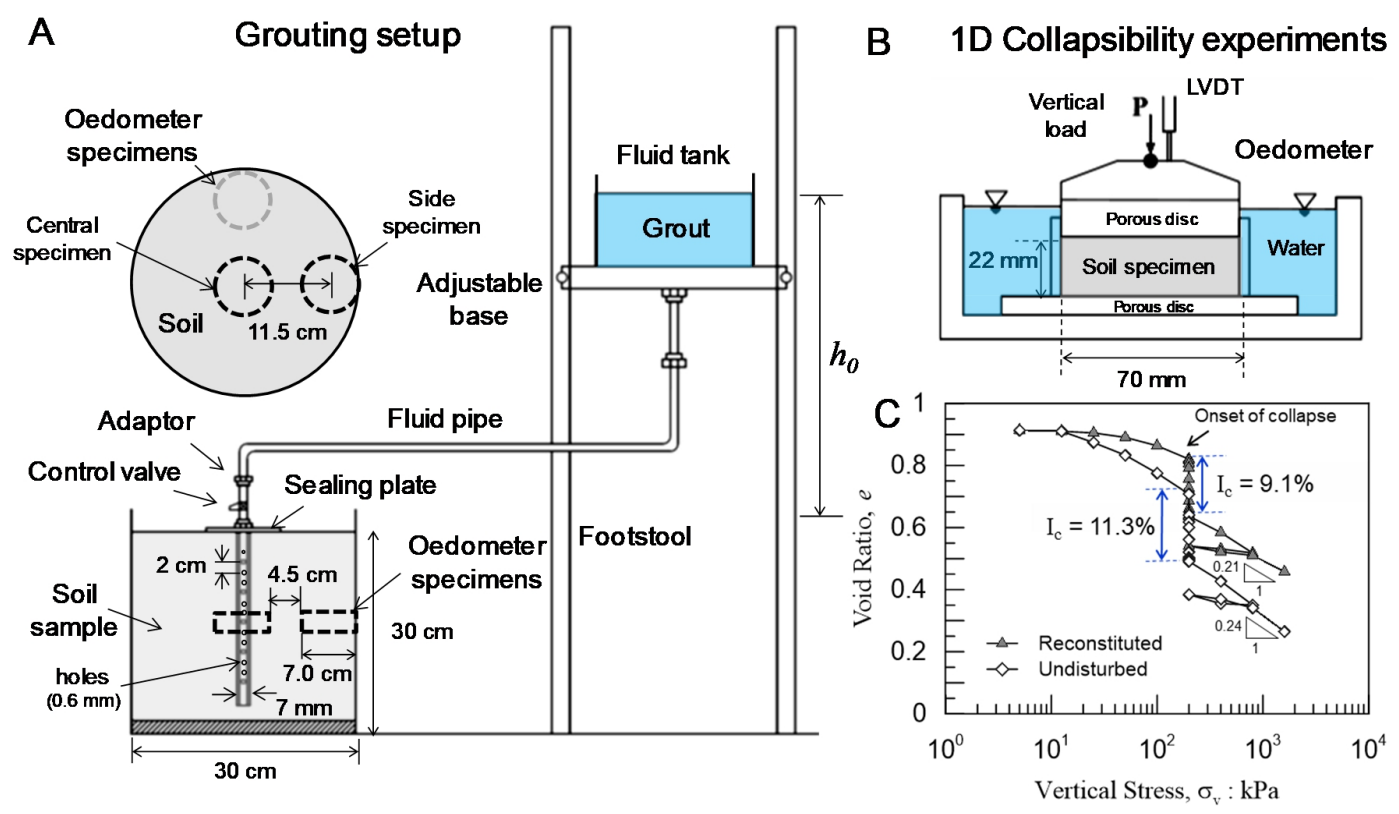

Fig. 3. (A) Experimental setup developed for grouting the loess deposit studied here. (B) 1-D measurement of the collapse potential in oedometer cell. (C) Compressibility and collapse behavior of undisturbed and reconstituted specimens of the untreated loess obtained in the oedometer cell. 

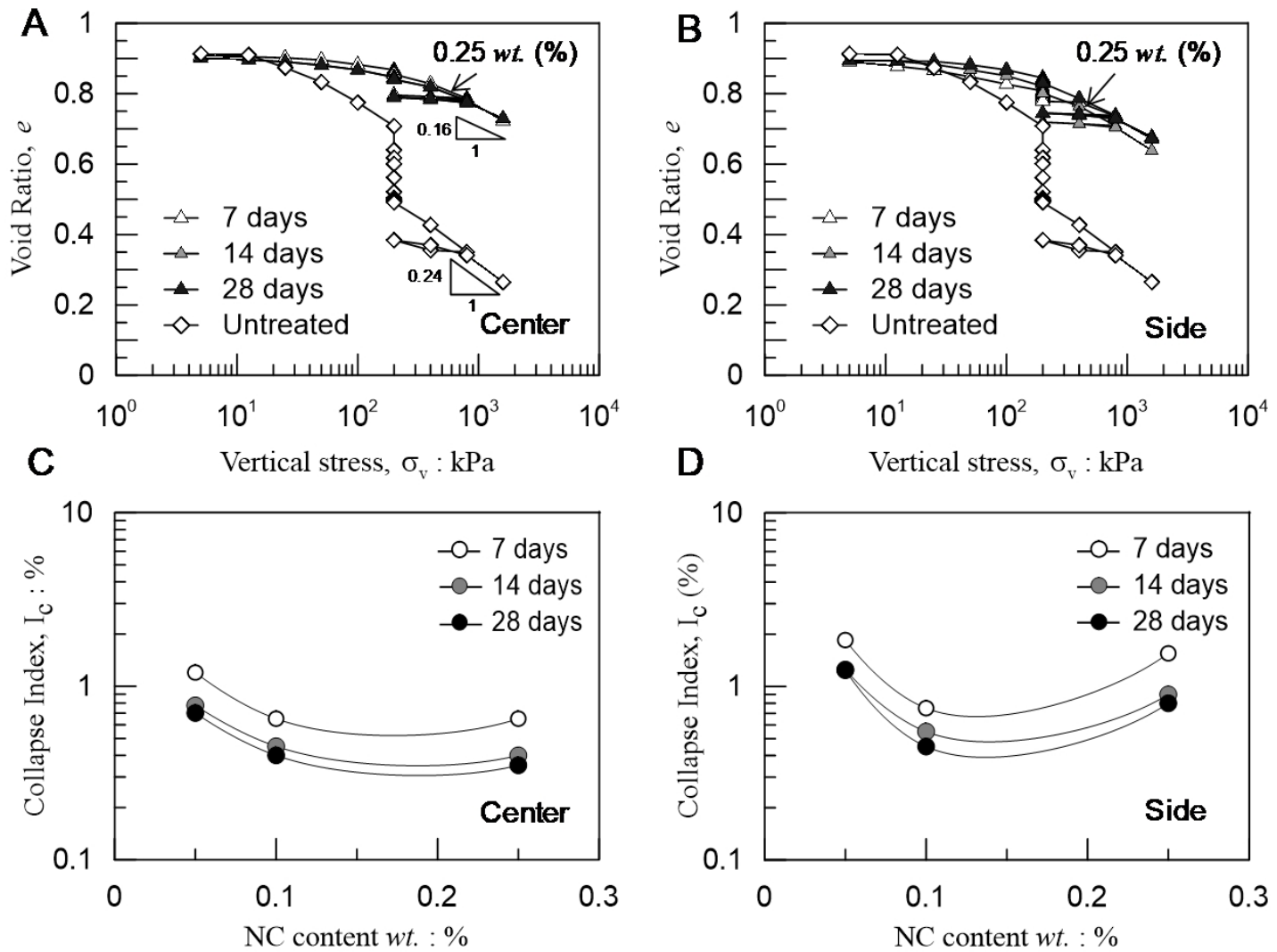

Fig. 4. Mechanical stabilization of the studied loess through grouting montmorillonite clay nanoparticles (NC): (A), (B) compressibility and collapse behavior of the untreated and grouted materials for specimens acquired from the center and side of the grouted column. (C), (D) variation of collapse index at different NC contents and curing times after grouting for the center and side specimens, respectively. 

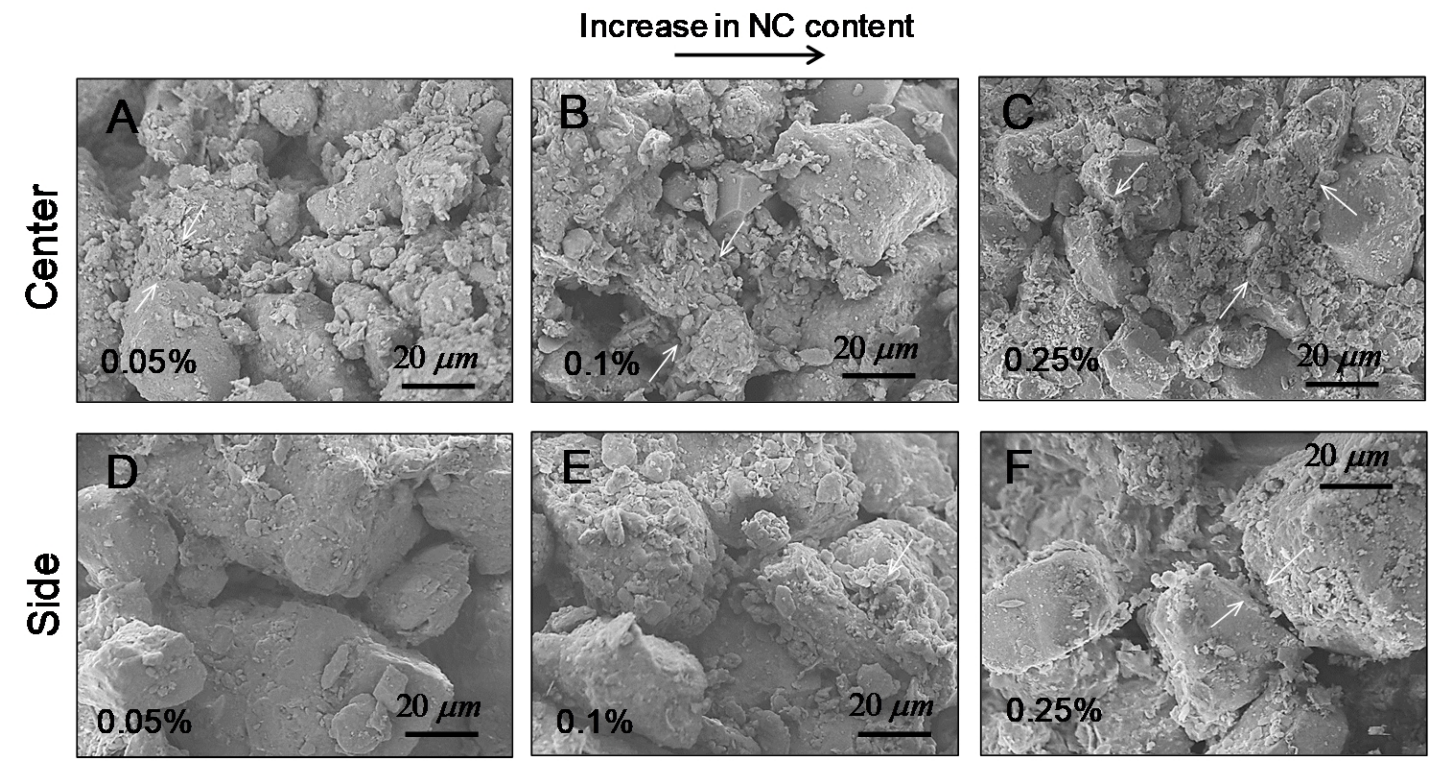

Fig. 5. SEM photomicrographs showing the microfabric of the grouted soil material using montmorillonite clay (NC) at various contents. The clay agglomerates are observed to likely bind the soil aggregates by forming interparticle bonds and fill the inter-aggregate pore space, particularly at larger contents. The arrows show the inter-grain/aggregate bonds formed by the clay assemblies. 

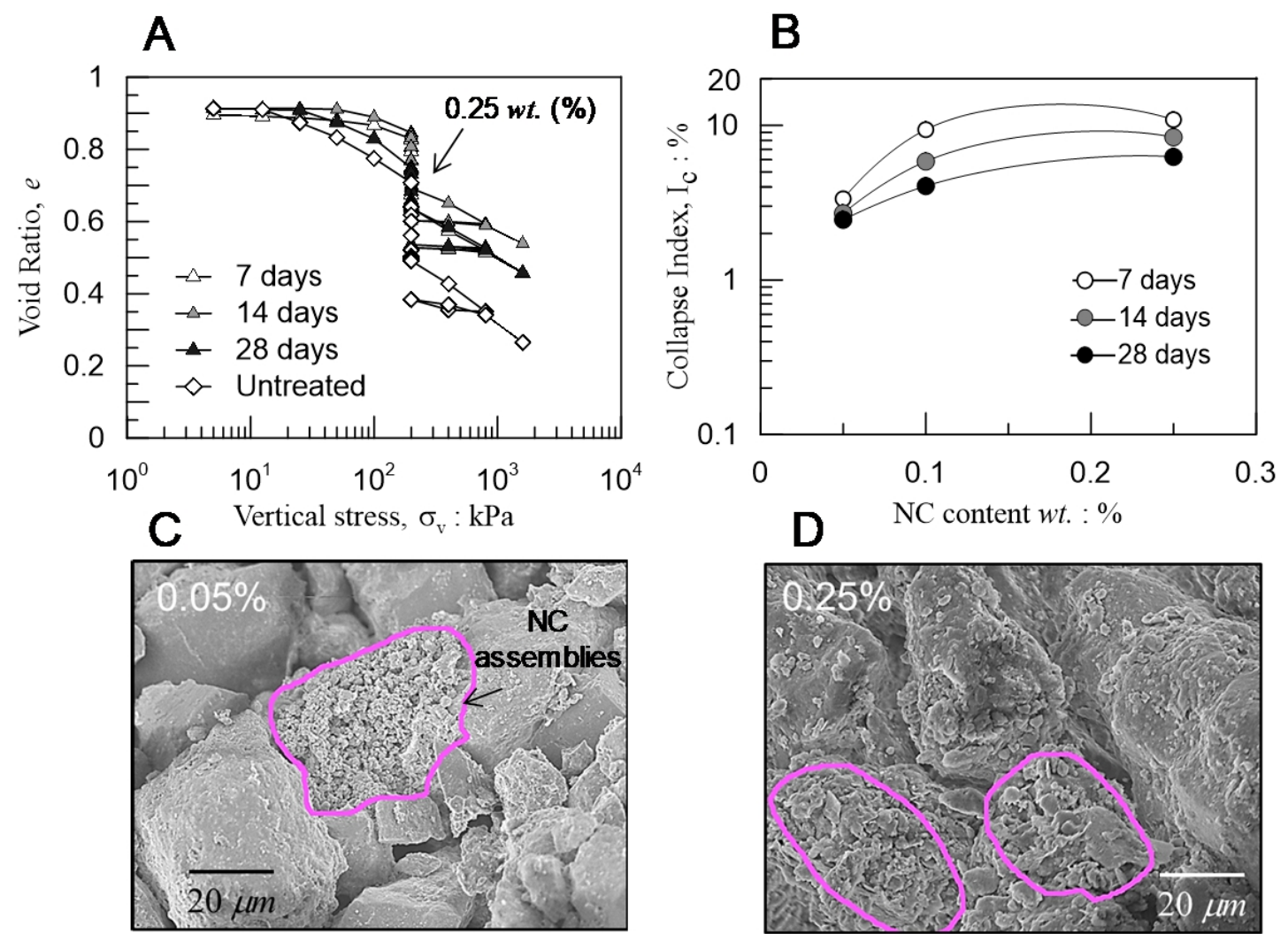

Fig. 6. Mechanical stabilization of the studied loess by mixing the soil with montmorillonite clay nanoparticles: (A) and (B) Compressibility and collapse behavior as a function of NC content. (C), (D) NC particle assemblies do not necessarily form interparticle bonds at the soil grain contact points. 

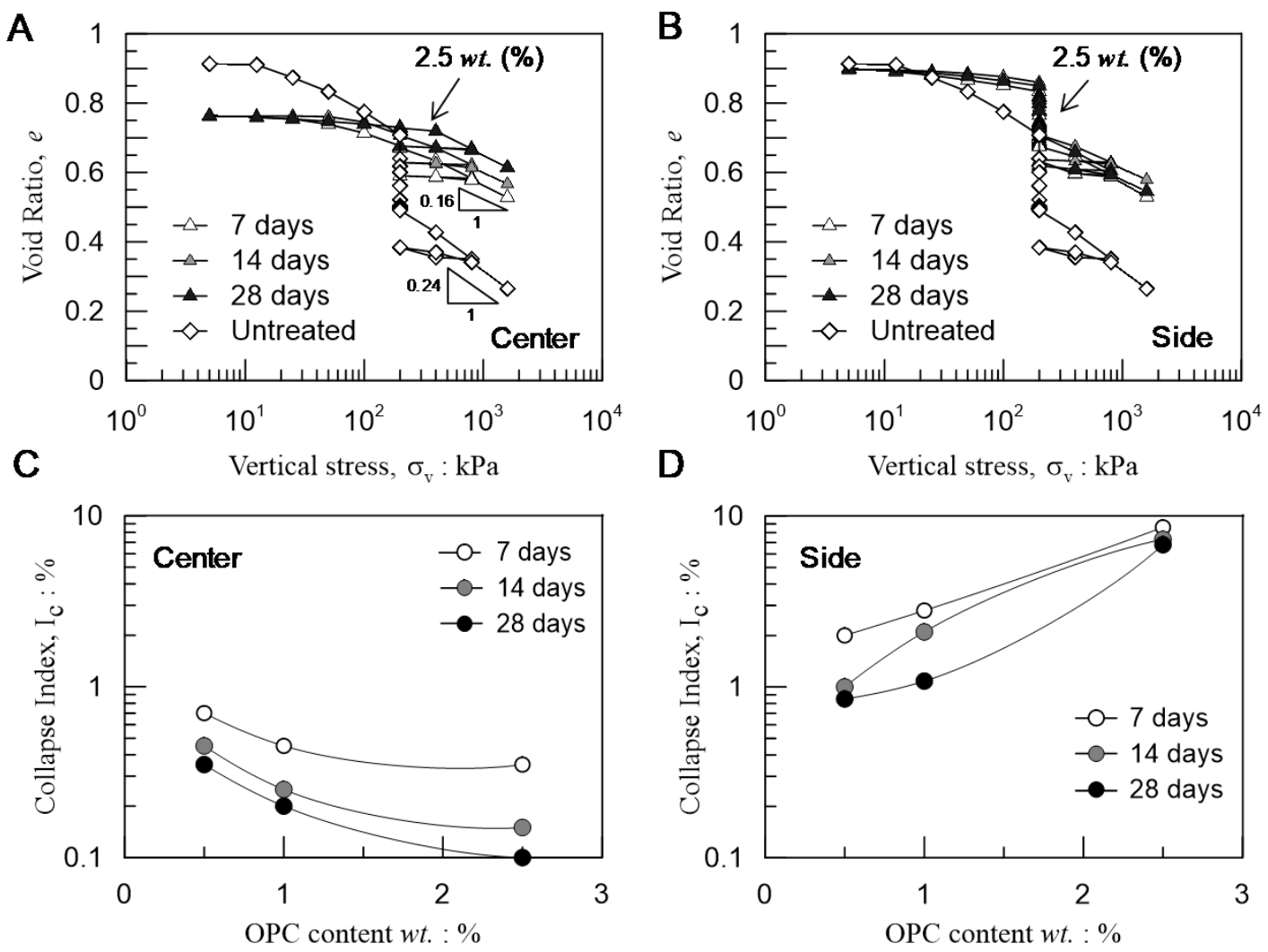

D Vertical stress, $\sigma_{\mathrm{v}}: \mathrm{kPa}$

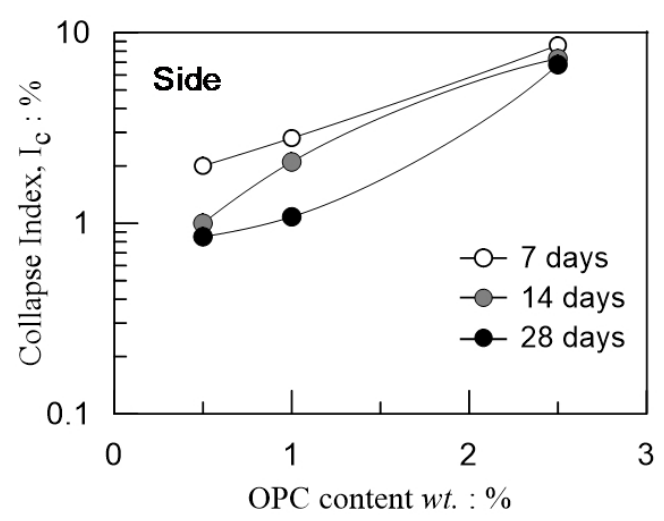

Fig. 7. Mechanical stabilization of the studied loess through grouting ordinary Portlant cement (OPC): (A), (B) compressibility and collapse behavior of the untreated and grouted materials for specimens acquired from the center and side of the grouted column. (C), (D) variation of collapse index at different OPC contents and curing times after grouting for center and side specimens, respectively. 

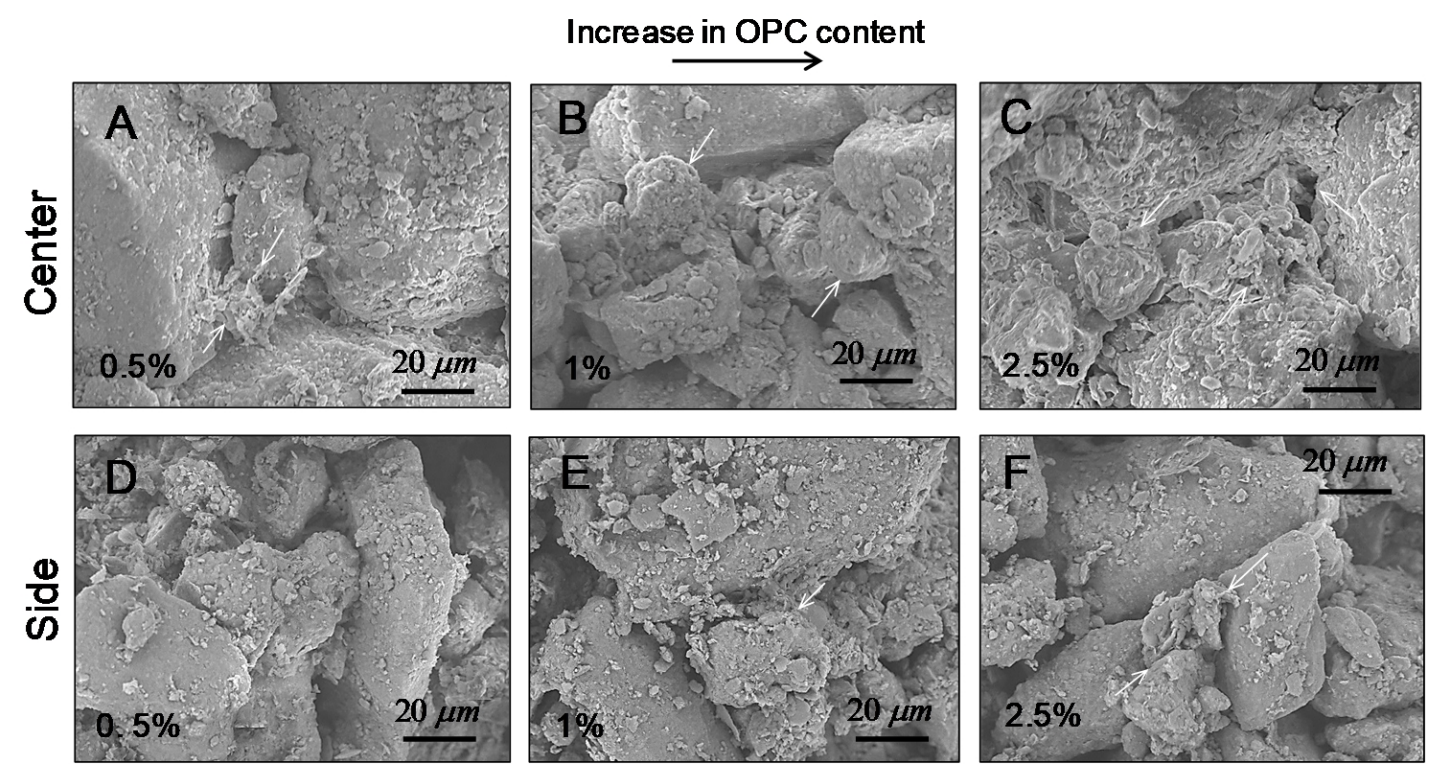

Fig. 8. SEM photomicrographs showing the microfabric of the grouted soil material using Portland cement (OPC) at various contents. The arrows show the intergrain/aggregate bonds formed by the cement bonds. 

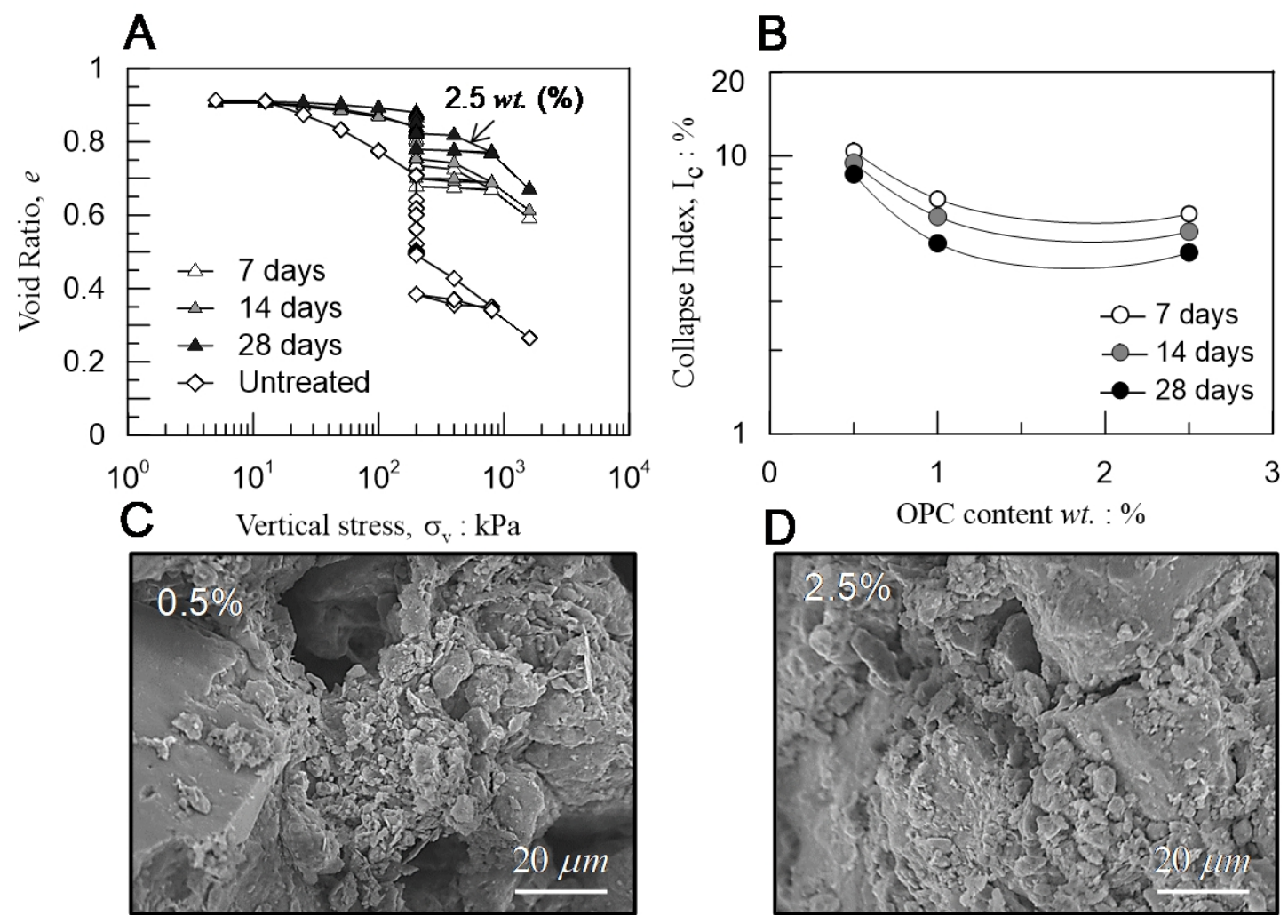

Fig. 9. Mechanical stabilization of the studied loess by mixing the soil with Portland cement (OPC): (A) and (B) compressibility and collapse behavior as a function of OPC content. (C), (D) SEM images showing the cement particles forming the intergrain/aggregate bonds within the soil matrix. 


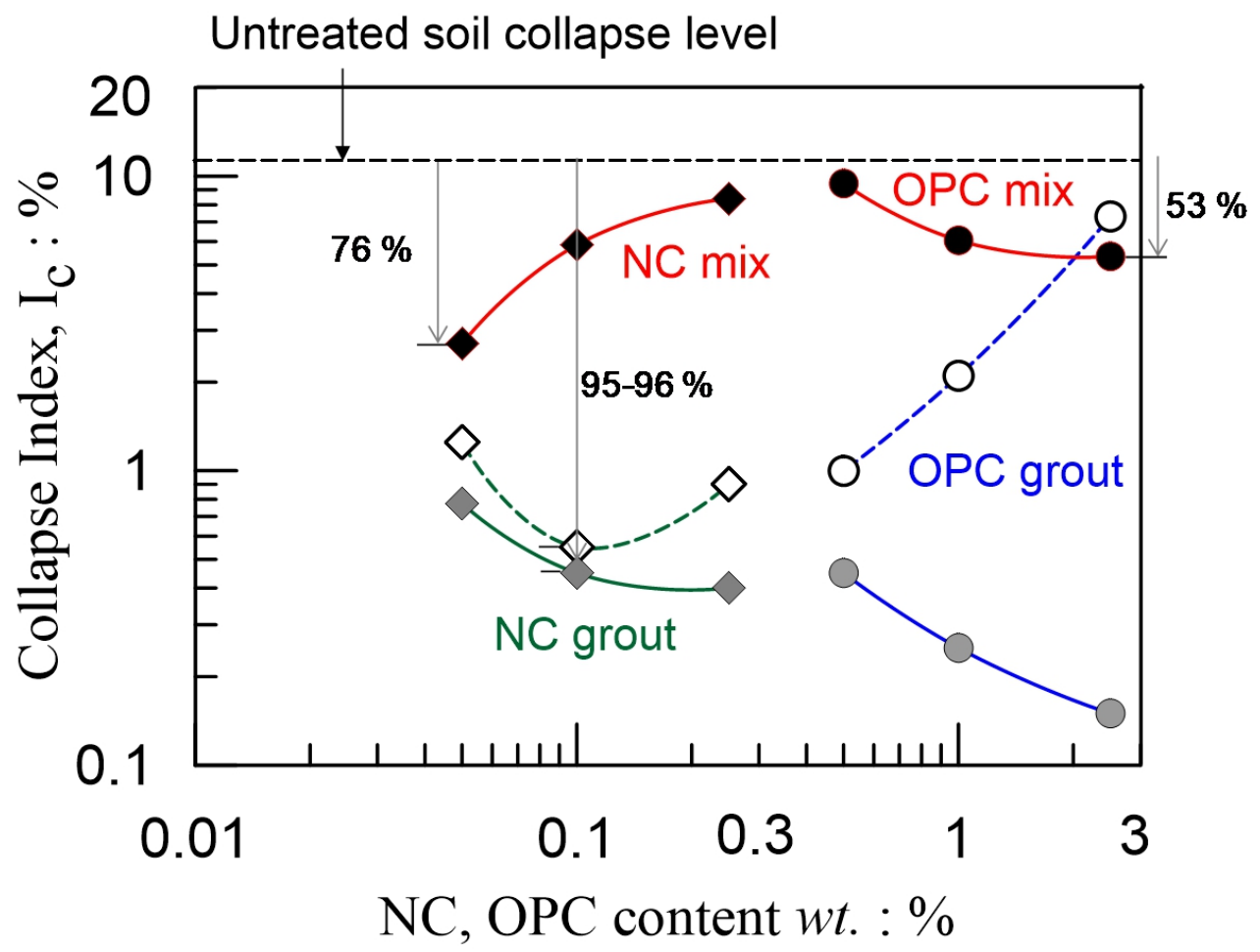

Fig. 10. Mechanical stabilization of the loess material studied here through grouting the NC and OPC solutions or mixing the stabilizer particles with soil for 14 days curing time. In grouting data, the dashed and solid lines represent the side and center specimens, respectively. 


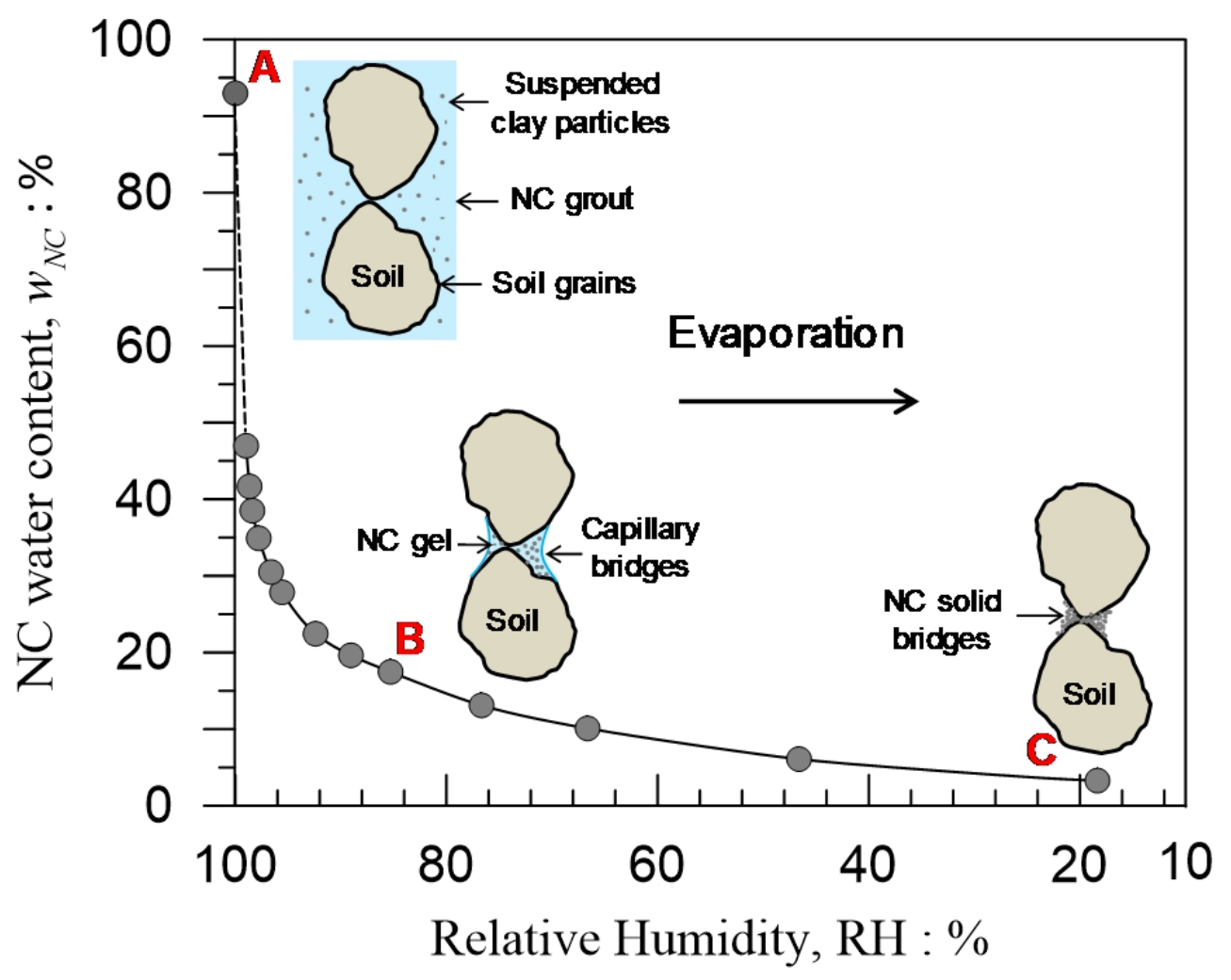

Fig. 11. Formation of interparticle bonds during evaporation of the montmorillonite clay (NC) grout after injection. Capillary suction condense clay particles in the capillary bridges, where the clay gel turns into solid bridges after evaporation 